\title{
Marxismo e feminismo: perspectivas políticas para a sociologia
}

\author{
Marxism and feminism: \\ political perspectives for sociology
}

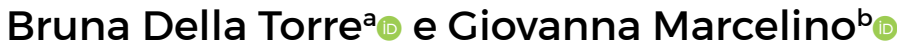

O feminismo envolve muito mais do que a igualdade de gênero. E envolve muito mais do que gênero.

O feminismo deve envolver uma consciência em relação ao capitalismo [...]. O feminismo insiste em métodos de pensamento e de ação que nos encorajam

a uma reflexão que une coisas que parecem estar separadas e que desagrega coisas que parecem estar naturalmente unidas (Angela Davis, A liberdade é uma luta constante, 2018)

No início de O Segundo Sexo, publicado pela primeira vez em 1949, Simone de Beauvoir (2016, p. 11)afirmava que "um homem não teria a ideia de escrever um livro sobre a situação singular que ocupam os machos na humanidade". Entretanto, cada vez que uma mulher quer escrever sobre sua situação, ela é obrigada a declarar "sou uma mulher", o que, por sua vez, suscita a pergunta que passa, então, a ter que responder: "o que é uma mulher?" (Beauvoir, 2016, p. 11). O livro de Beauvoir parte justamente da crítica à tentativa de isolar as interpretações das mulheres sobre si mesmas e sobre o mundo para analisar a própria produção da "mulher" enquanto um processo.

Os movimentos feministas até hoje permanecem debatendo se podem prescindir de uma identidade de gênero (Butler, 2016) ou se, com a derrocada da categoria "mulher", a própria noção de "feminismo" perderia seu alicerce (Federici, 2020). Esse debate é fundamental e suas consequências são amplas, mas sua permanência é a prova de que, de uma forma ou de outra, o feminismo é sempre interpelado a fornecer uma resposta a esse problema sobre o lugar e a pertinência

a Pesquisadora visitante no Käte Hamburger Kolleg für Apokalyptische und Postapokalyptische Studien (CAPAS)/Heidelberg, pós-doutoranda no departamento de Sociologia da Unicamp (bolsista Fapesp) e editora executiva da revista Crítica Marxista.

b Doutoranda em Sociologia na Universidade de São Paulo e pesquisadora visitante na King's College de Londres. 
de pensar a questão feminina. Um movimento no campo da teoria e da política que historicamente não deixou de produzir reações diversas, como a tentativa de reduzir todo o debate complexo desenvolvido pelo feminismo a uma discussão singular, isolada e, como se diz hoje em círculos mais reativos, "identitária".

Na contra tendência desse esforço social e acadêmico de isolamento, o objetivo deste dossiê foi pensar o feminismo como uma perspectiva política a partir da qual é possível ampliar o alcance do marxismo e da teoria social. Conforme afirmou Angela Davis (2018, p. 40), trata-se de pensar o feminismo menos como "algo enraizado em corpos marcados pelo gênero" e mais como "uma forma de interpretação conceitual, uma metodologia, como um guia para as estratégias de luta".

Nos últimos anos, o movimento feminista tem ganhado força no mundo inteiro e, principalmente, na América Latina. Esse novo fôlego tem transformado as relações de poder nos partidos, nos movimentos sociais, na academia, como também tem produzido novas interpretações sobre o capitalismo. As mulheres, a população racializada e LGBTQI+ são as principais responsáveis pela "retomada de Marx" (Musto, 2021) após a crise de 2008, acompanhada de uma retomada do feminismo, o que permitiu investigar a crise capitalista também a partir da perspectiva de sua reprodução. O feminismo amplia, assim, a interpretação da crise capitalista em sua dimensão múltipla de gênero, sexualidade, raça, geopolítica, ecológica. Conforme mostrou Silvia Federici (2017), o processo de acumulação primitiva capitalista construiu-se historicamente a partir de uma "guerra contra as mulheres”. Esse processo é, hoje, atualizado pela precarização, violência e endividamento produzidos pelo neoliberalismo (Gago, 2020).

O florescimento recente dos feminismos também tem produzido mudanças nas ciências sociais e naquilo que é considerado seu cânone. Por que Émile Durkheim é considerado um clássico da sociologia e Simone de Beauvoir não? Por que ler Florestan Fernandes, mas não ler também Heleieth Saffioti e Lélia Gonzalez? Por que uma teórica crítica tão fundamental como Angela Davis normalmente fica restrita aos cursos sobre gênero e raça? Quais são os critérios de construção do cânone? E, mais importante que isso, o que as teorias da sociedade perdem de vista ao deixarem de lado as várias perspectivas feministas? A crítica feminista ao cânone não busca, assim, simplesmente "resgatar" autoras submetidas, pela sua condição de gênero e/ou raça e sexualidade, a um apagamento e silenciamento histórico, mas mostrar como suas contribuições teóricas expandem a compreensão da sociedade contemporânea. 
Nessa chave, o presente dossiê reúne uma série de reflexões que visam abordar criticamente o chamado "cânone" da teoria social e do próprio marxismo e mobilizar a perspectiva feminista para a compreensão do presente histórico.

O dossiê conta com três traduções. A primeira delas, de Flora Tristan, "Necessidade de acolher bem as mulheres estrangeiras" (1835), traduzido por Lilian Vilanova e Luna Ribeiro Campos, trata de um novo sujeito que surge com a modernização capitalista na Europa, e dos novos fluxos humanos que ela produz: a mulher "sozinha e estrangeira" nas grandes capitais. Tristan foi uma escritora franco-peruana socialista, cujas obras mais conhecidas são Peregrinações de uma pária (1938) e União operária (1843). Seus textos, como é o caso da tradução publicada neste dossiê, são fortemente marcados pela experiência da "viagem" presente em sua trajetória como ativista e por um vocabulário evangelizante, próximo do socialismo utópico. Apesar desse último elemento, Tristan presenta uma série de considerações materialistas a respeito da condição das mulheres sob o capitalismo e da relação da instituição familiar com a opressão feminina. Em "Necessidade de acolher bem as mulheres estrangeiras", Tristan aborda dois temas que permanecem extremamente atuais: a questão da imigração e as condições às quais as mulheres imigrantes estão submetidas nas grandes cidades capitalistas e a necessidade de pensar essa questão, tanto política, quanto teoricamente, a partir de uma perspectiva internacionalista.

O dossiê conta também com o panfleto "Sobre a greve geral” (1974), de Mariarosa Dalla Costa, traduzido por Bruna Della Torre. Dalla Costa foi membra do Potere Operaio, uma das fundadoras da organização Lotta Feminista, na Itália, e expoente importante da "Campanha internacional por salários para o trabalho doméstico" na década de 1970. Esse panfleto teve uma importância histórica central na construção da greve feminista e no desenvolvimento das teorias da reprodução social, ao expor o caráter restritivo da noção de greve construída a partir da paralisação apenas dos trabalhadores fabris assalariados. Suas questões permanecem atuais não só no âmbito teórico, mas igualmente no espectro político, uma vez que a greve feminista tem sido um dos principais instrumentos de luta do movimento contemporâneo.

A terceira tradução presente neste dossiê é "Da opressão à independência. A filosofia do amor em O Segundo Sexo", de Manon Garcia. Traduzido por Ana Flávia P. L. Bádue, o artigo de Garcia aborda como Beauvoir reflete sobre a dominação masculina como algo fundado e justificado pelo amor. Para além da crítica à monogamia, também presente em Beauvoir, trata-se de mostrar como o mito de uma natureza feminina fixa (o eterno feminino, por exemplo) está diretamente 
ligado à objetificação das mulheres e à negação de sua condição de sujeito, legando às mesmas um destino único: o de serem possuídas pelo homem. Autora de Não se nasce submissa, torna-se (2018), Garcia propõe uma interpretação inédita da obra de Beauvoir, não apenas como uma teórica do "gênero", mas como alguém que produz uma filosofia política da liberdade a partir de um dos grandes tabus da sociedade moderna, a experiência da submissão.

Além disso, o dossiê conta com 7 artigos inéditos. Em "Socialismo, gênero e trabalho: uma análise da União Operária, de Flora Tristan”, Luna Ribeiro Campos "resgata a contribuição de Flora Tristan, situando sua obra em relação ao contexto histórico e à tônica dos debates ocorridos no interior da tradição socialista, do feminismo e do pensamento social no século XIX. O artigo faz uma análise de União Operária, obra na qual Tristan elaborou - cinco anos antes de Marx e Engels escreverem o Manifesto Comunista - uma proposta pioneira de associação internacional de trabalhadores, advogando que a união dos trabalhadores não seria possível sem a organização das mulheres, bem como um projeto de emancipação não seria viável sem a defesa de igualdade absoluta entre homens e mulheres.

Em "Do contrato sexual ao reconhecimento: repensando a prostituição por um olhar teórico-crítico", Tarine Guima Gonçalves e Thaís de Almeida Lamas debatem outro tema central da teoria feminista, que igualmente remonta aos debates do socialismo clássico: a questão da prostituição. Na tentativa de oferecer um olhar renovado sobre o tema, as autoras não apenas oferecem um resgate crítico sobre as maneiras pelas quais ele foi tratado pelos/as socialistas do século XIX e XX, como propõem uma forma alternativa e atualizada para se pensar a questão, nos marcos da teoria crítica contemporânea. Para tanto, o artigo propõe um encontro e diálogo crítico entre duas abordagens: as noções de contrato sexual e patriarcado desenvolvidas por Carole Pateman e a teoria crítica da justiça de Nancy Fraser, trabalhando os desencontros e aproximações possíveis entre tais autoras para uma análise sobre a prostituição atualmente.

Em "Las mujeres em Lefebvre: por una relectura del espacio urbano desde los feminismos marxistas”, Almendra Aladro propõe repensar a teoria lefebvreana sobre a produção do espaço social no capitalismo a partir das lentes das teorias marxistas feministas da reprodução social, buscando uma conexão das mesmas com a realidade das cidades latinoamericanas. A autora resgata, em primeiro lugar, o quanto as análises feministas da acumulação primitiva oferecem aportes fundamentais à teoria de Lefebvre, ao aprofundar o lugar das mulheres no processo histórico e violento de conformação das cidades durante a transição para o capitalismo. Além disso, elucida como os feminismos da reprodução social 
permitem uma compreensão mais alargada do papel das mulheres nas metrópoles contemporâneas, assim como nas lutas por reapropriação do urbano diante dos processos atuais de espoliação capitalista nesse âmbito.

Já em "Produzir na reprodução: um olhar sobre a renovação da força de trabalho escrava no Brasil oitocentista”, Gabriela Salcedo Figueira mobiliza a teoria da reprodução social para pensar a escravidão no Brasil. Para isso, a autora investiga a forma como a reprodução da população escravizada ocorreu no país e como ela desempenhou um papel central na crise do modelo escravista, se valendo da análise de manuais de agricultura escritos por senhores de escravos no século XIX. Ao localizar o controle dos corpos das mulheres escravizadas no problema da reprodução da força de trabalho, o artigo reforça o quanto generificação e racialização são elementos indispensáveis para a interpretação da constituição do capitalismo brasileiro, bem como sobre seu lugar na reprodução do capitalismo mundial.

Em "A violência contra as mulheres e o movimento feminista dos anos 1970 nos EUA a partir de Nancy Fraser e Angela Davis”, Barbara Cristina Soares Santos mobiliza igualmente as relações entre gênero e raça, mas no intuito de pensar outro tema fundamental da teoria social feminista marxista: a questão da violência contra as mulheres. Para isso, resgata as intervenções de Angela Davis e Nancy Fraser sobre o tema, de forma a explorar como a questão racial se encontra no centro das diferenças políticas e epistemológicas entre as autoras, algo que estaria relacionada, por sua vez, à forma como cada uma delas interpretou os sentidos das mobilizações feministas norte-americanas nos anos 1970.

Os dois últimos artigos que encerram a sessão promovem uma aproximação entre ontologia marxista e feminismo. Partindo da problematização a respeito da marginalização das mulheres na tradição ontológica ancorada em Marx e Lukács, Tábata Berg promove, em “A ontologia marxista na perspectiva do ser-outra”, uma releitura das abordagens sobre o ser social pela ótica da epistemologia feminista, propondo a categoria "ser-outra", em oposição à noção de sujeito universal. Em chave diversa, Lívia de Cássia Godoi Moraes, em "Relação entre universal, particular e singular em análises feministas marxistas: por uma ontologia integrativa”, resgata a centralidade da dialética e da leitura feminista marxista da categoria da totalidade, realizada pelas teóricas da reprodução social desde os anos 1970, para se pensar a sociabilidade capitalista e as diferentes formas de opressões de classe, gênero, raça e sexualidadede forma integrativa, tendo em vista que o capitalismo é um sistema unitário estruturado por múltiplas teias de relações opressivas. 
Por fim, o dossiê apresenta uma entrevista com Maria Lygia Quartim de Moraes, uma das mais importantes feministas marxistas no Brasil. Conduzida por Danielle Tega, a entrevista tem como tema principal a trajetória de Quartim de Moraes, sua militância contra a ditadura, seus estudos sobre o feminismo e sua atuação político-acadêmica nas últimas décadas. Mas a entrevista não se reduz a um depoimento "pessoal”. A partir da trajetória de Quartim de Moraes é possível entrever as questões de uma época, bem como os dilemas da construção do marxismo feminista no Brasil.

Esperamos que esse dossiê possa colaborar com os debates sobre feminismo, marxismo e teoria social nas ciências sociais e que ele possa igualmente inspirar a construção de debates e relações mais igualitárias em termos de gênero, classe, sexualidade e raça na academia. Num momento no qual a classe trabalhadora, as feministas, a população LGBTQIA+, bem como as populações negra e indígena estão sob a mira do canhão do neofascismo no Brasil, enquadrados juntos como a grande ameaça "comunista" ao país, agradecemos à revista Plural pelo espaço para construir um debate crítico a respeito dessas questões. Agradecemos também a todas as pesquisadoras que atuaram como pareceristas e contribuíram para a publicação deste dossiê. Finalmente, gostaríamos de agradecer à coletiva "Marxismo feminista", nascida da organização do Primeiro Seminário Internacional Marxismo Feminista da USP, que iria ocorrer em 2020, mas teve que ser postergado devido à pandemia de COVID-19. Este dossiê nasceu dos debates que também fizemos em grupo e, por isso, agradecemos às companheiras que nos acompanham nessa travessia.

\section{REFERÊNCIAS BIBLIOGRÁFICAS}

BEAUVOIR, Simone (2016). O segundo sexo. Rio de Janeiro: Nova Fronteira.

BUTLER, Judith (2016). Problemas de gênero: feminismo e subversão da identidade.

Rio de Janeiro: Civilização Brasileira.

DAVIS, Angela (2018). A liberdade é uma luta constante. São Paulo: Boitemp.

FEDERICI, Silvia (2020). Beyond the periphery of the skin. Rethinking, Remaking, and Reclaiming the Body in Contemporary Capitalism. Oakland: PM Press.

FEDERICI, Silvia (2017). O Calibã e a bruxa: mulheres, corpo, acumulação primitiva.

Tradução de Coletivo Sycorax. São Paulo: Editora Elefante.

GAGO, Verónica (2020). A potência feminista ou o desejo de transformar tudo. São Paulo: Elefante.

MUSTO, Marcelo (org) (2020). The Marx Revival. Key concepts and new interpretations.

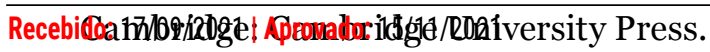

